\title{
SISTEMA DE INFORMAÇÃO E CIDADANIA: A FALTA DE USABILIDADE CONTINUA IMPEDINDO O PLENO EXERCÍCIO DA DEMOCRACIA?
}

\author{
Ana Paula de Carvalho ${ }^{1}$ \\ Moisés Henrique Ramos Pereira ${ }^{2}$ \\ Cayley Guimarães \\ Bráulio Roberto G.M. Couto \\ 1 anapaulacdv2000@gmail.com; ${ }^{2}$ moiseshrp@ gmail.com; ${ }^{3}$ profcayley@ yahoo.com.br; \\ bcouto@unibh.br \\ Curso de Ciência da Computação - Uni-BH (www.unibh.br)
}

\begin{abstract}
Resumo - A Internet possui um papel importante na sociedade do conhecimento, principalmente no que se refere à popularização da informação, atuando como vetor importante no processo democrático social. Os candidatos políticos têm na Internet um espaço abrangente e globalizado para disseminar suas campanhas. Nesta pesquisa avaliam-se os sites de candidatos políticos nas eleições de 2008 em Belo Horizonte e percebe-se a falta de usabilidade desses sites, dificultando o acesso às informações relevantes $e$ ao exercício da cidadania no processo decisório eleitoral. Palavras-chave - usabilidade, informação, cidadania.
\end{abstract}

\begin{abstract}
The Internet has an important role in the knowledge society, especially with regard to the popularization of information, acting as an important vector in the social democratic process. The political candidates find on the Internet a comprehensive and global space on which to disseminate their campaign. This study evaluate the sites of political candidates in the elections of 2008 in Belo Horizonte and notices a lack of usability of these sites, hindering access to relevant information and the exercise of citizenship in decisionmaking election.
\end{abstract}

Keywords - usability, information, citizenship.

\section{INTRODUÇÃo}

$\mathrm{Na}$ sociedade do conhecimento, percebe-se fortemente a importância do acesso à informação. A Internet passa a ser, cada vez mais, um poderoso meio de comunicação e informação para diversas áreas das atividades humanas, incluindo a política. Neste cenário, a Internet constitui-se uma ferramenta a ser ampla e estrategicamente usada na divulgação e democratização das propostas dos candidatos através dos seus sites (SORJ, 2003).

Santana \& Guimarães (2006) analisam a usabilidade dos sites dos candidatos políticos concluindo que este importante meio de comunicação não é bem empregado para a promoção da democracia. O presente trabalho reproduz a metodologia utilizada por Santana \& Guimarães (2006) para análise da usabilidade de sites políticos da atual campanha e do seu impacto na democracia, e realiza uma comparação destes dois momentos históricos, constatando que a situação agravou, persistindo a falta de usabilidade em prejuízo à democracia.

\section{CidadANia Na Sociedade da INFORMAÇÃo}

Conforme Guarinello (2003), o conceito de cidadania, oriundo da sociedade grego-romana, defini-se pela composição de elementos como "[...] democracia, participação popular nos destinos da coletividade, soberania do povo, liberdade do indivíduo". Já para Dalmo Dallari (1998), "A cidadania expressa um conjunto de direitos que dá à pessoa a possibilidade de participar ativamente da vida e do governo de seu povo. Quem não tem cidadania está marginalizado ou excluído da vida social.".

$O$ exercício de cidadania faz-se necessário e visivelmente presente nos direitos civil, sócio-econômico e político. No direito político, cada indivíduo é um ser atuante que pode definir o futuro da sociedade por meio da representação máxima da democracia que é o direito ao voto. Para Gentilli (2002), "o alargamento da participação na cidadania pressupõe um alargamento do direito à informação como uma premissa indispensável, 
um pressuposto". Enfim, os cidadãos devem ter acesso à informação para que possam discernir e determinar o seu julgamento perante os assuntos políticos, pois, em caso contrário, seu poder de decisão e escolha consciente podem ser prejudicados, provocando o tolhimento da democracia. Isto é válido para a escolha do candidato, pois a falta de usabilidade impede acesso à informação.

\section{Mídias e Política}

A forma de divulgação das idéias políticas, por parte dos candidatos, foi se aperfeiçoando com o surgimento de novas tecnologias e meios de comunicação. A princípio, os candidatos se valiam de discursos em praça pública. Posteriormente, a escrita passou a ser um recurso usado nas campanhas políticas. Em seguida, o rádio e a televisão agregaram novas oportunidades de comunicação: o rádio acrescentou novos espaços de comunicação e exposição de idéias, promovendo uma popularização das campanhas; por sua vez, a televisão, além de popularizar, possibilitou a inserção de novos recursos visuais e de marketing, tirando o conteúdo e transformando em espetáculo. A Internet expande todas essas possibilidades, gerando novas abordagens de expressão, sendo, portanto, uma evolução dos meios de comunicação (SORJ, 2003).

A Internet tem como diferencial a possibilidade de uma comunicação instantânea que desconsidera questões tradicionais de espaço físico e de tempo e, ainda, promove um novo contexto político-social, possibilitando convergência entre informação e comunicação, permitindo assim uma participação descentralizada (SORJ, 2003). Conforme Santana \& Guimarães (2006), “[...] pode-se dizer que a Internet oferece certa vantagem sobre os meios tradicionais e até mesmo que tenha se tornado ideal no que se refere a uma comunicação democrática".

A propaganda eleitoral, na Internet, será permitida apenas na página do candidato destinada unicamente a este fim, podendo possuir a terminação "can.br" ou outras. O candidato interessado deverá cadastrar a página no órgão gestor da Internet seguindo o formato: http://www.nomedocandidatonumerodocandidat o.can.br. Os sites com a terminação "can.br" serão automaticamente cancelados após a votação em primeiro turno, exceto os sites dos candidatos que irão concorrer ao segundo turno, que serão cancelados após esta votação (BRASIL, 2006).

Segundo Balboni (2008), o Brasil possui atualmente 45 milhões de usuários da Internet, representando $24 \%$ da população total. Constatase então uma significativa evolução no número de usuários da rede, apresentando um crescimento de cerca de 10 milhões de usuários em comparação com o ano de 2006. Esses índices ressaltam a importância deste novo meio de comunicação no âmbito político. Por outro lado, como os candidatos são muitos e a legislação restringe alguns elementos de campanha como propaganda, comício, a Internet torna-se alternativa para que o candidato, com o pouco tempo existente na TV, direcione os eleitores para seu site, onde suas propostas e informações sejam visualizadas dentro do tempo que o cidadão quiser estipular. Em pesquisa realizada pelo IBOPE (2006) apud Coutinho (2008), a TV registrou $76 \%$ na preferência de uso por parte dos entrevistados, demonstrando que ainda é o principal veículo para disseminação de informações políticas, mas a Internet também se projeta como um meio de comunicação relevante no contexto político, favorecendo o acesso consciente à informação por parte dos eleitores.

Coutinho (2008) analisa o caso do candidato presidencial americano, Barack Obama, que está inovando no que tange à propaganda política, não se restringindo apenas aos recursos e ferramentas utilizadas na Internet, mas, principalmente, pela intensidade e foco diferenciado que a ferramenta propicia, 
arrecadando milhões de dólares através de contribuições de seus eleitores em blogs e sites de relacionamento.

Para Maia (2002), o ambiente de conexão (espaço para opinar livre e publicamente), a complexidade de conteúdos (extensa rede de diferentes informações que requer usabilidade para melhor produtividade) e o sistema de interações (oportunidade de interação entre os indivíduos através de diversas aplicações) são as características que fazem da Internet um espaço virtual público de informações. Dessa forma, ela permite ao cidadão realizar o seu direito político e exercer a cidadania dentro do processo democrático, incluindo aqui a obtenção de informações sobre os candidatos.

\section{SiSTEMAS DE INFORMAÇÃO E USABILIDADE}

O sucesso de aceitação de um sistema de informação (SI) é diretamente proporcional à sua interação e integração com o ambiente social onde se encontra (OLIVEIRA, 2003). Segundo Laudon \& Laudon (2004), os sites de candidatos políticos podem ser considerados como sistemas de informação, pois oferecem funções técnicas ou administrativas que estão presentes no cotidiano da sociedade.

Dentro da área de interação homemmáquina, Sorj (2003) aponta a necessidade de que essas novas tecnologias tenham boa usabilidade nas tarefas demandadas pelos seres humanos, a fim de que o serviço ali oferecido seja socialmente aceito, promovendo qualidade de vida e integração social para os seus usuários. A usabilidade se efetiva no sistema quando esse permite que os usuários consigam, com facilidade, alcançar e executar seus objetivos. Para Carroll \& Moran (1996), a facilidade no momento do uso, percepção e recuperações dos erros, compreensão facilitada para utilizar o sistema, ao executar uma tarefa, e sucesso nessas execuções são características principais, necessárias para que um sistema apresente boa usabilidade. Dessa forma, quando um SI não apresenta usabilidade, surgem problemas, pois os usuários terão dificuldades em realizar suas tarefas com sucesso, podendo até mesmo resultar em fracasso na aceitação do mesmo pela sociedade. A falta de usabilidade nos sites, hoje, é um dos maiores problemas encontrados na Internet (CARROL \& MORAN, 1996).

É importante ressaltar o papel dos sites na atual conjuntura social, pois, como relevantes sistemas de informação, eles permitem a comunicação e difusão de dados, promovendo forte ligação entre os usuários e a Internet. Essa última se mostra como uma valiosa ferramenta para disponibilizar inúmeros tipos de informações aos seus usuários, mas quase sempre os sites não oferecem usabilidade clara, intuitiva e objetiva na organização dessas informações, dificultando a interação homemcomputador.

Nielsen (2006) apud Camargos (2006) informam que a simplicidade e o uso mais prático são itens muito importantes na organização da informação na navegação dentro dos sites. Se o design não apresentar facilidade de uso satisfatório, provocando dificuldades na usabilidade, os sistemas podem fracassar em vários aspectos. Enfim, a implementação de qualquer tecnologia da informação deve ter o ser humano como foco principal e, a partir disso, permitir boa interação entre o sistema e o usuário. A falta de usabilidade impede o acesso à informação (SORJ, 2003).

\section{Sistemas de InformaÇão e Política}

Atualmente, a Internet participa ativamente na vida de grande parte das pessoas, agregando meios para que elas possam exercer sua cidadania como processo democrático, possibilitando um aumento na qualidade $\mathrm{e}$ fiscalização das ações e serviços governamentais, projetando novas formas de participação política na gestão pública e alterando a própria estrutura político-social vigente (SORJ, 2003). Essa estrutura da 
sociedade se forma pela efetiva participação política do cidadão através do voto. Para isto, são realizadas campanhas eleitorais, momento em que os eleitores têm a oportunidade de acessar na Internet informações sobre os candidatos políticos. Este acesso pode ser considerado importante para o exercício da democracia ao proporcionar informação para escolha consciente.

Rubim (2001) afirma que a Internet está presente, ativamente, na vida política dos cidadãos, na proporção em que eles a utilizam para acessar informações sobre seus candidatos. A Internet promove uma nova realidade que possibilita inovações estratégicas na prática política, pois "[...] sem essas democratizações não existe efetivamente democracia hoje" (RUBIM, 2001). Estas inovações serão válidas somente quando os sites apresentarem melhor nível de usabilidade, ainda mais para sites de candidatos que, pelo fato de desconsiderar esse item de interação com os usuários, podem perder eleitores ou induzir o eleitor a um voto inadequado. É relevante investigar a falta de usabilidade nestes sites, pois os cidadãos devem ser capazes de acessar informações importantes dos candidatos, senão o objetivo de cidadania pode não ser alcançado, comprometendo a democracia.

\section{Pesquisa de Usabilidade}

A Internet, como descrito nas seções anteriores, possui características que permitem o exercício da cidadania. Por exemplo, a disponibilidade de informações dos candidatos políticos possibilita ao cidadão escolher de forma consciente seu candidato. Logo, faz-se necessário que os sites dos candidatos sejam planejados para possibilitar que os cidadãos, de forma eficiente, exerçam seus direitos políticos.

\subsection{Proposta de Pesouisa}

Esta pesquisa analisa os sites dos candidatos políticos, visando avaliar sua usabilidade e averiguar o impacto dos mesmos na cidadania. É realizado um estudo comparativo dos resultados obtidos neste estudo com a pesquisa de Santana \& Guimarães (2006), com o intuito de comparar os dois momentos históricos. A falta de usabilidade dos sites pode impedir o acesso à informação dos candidatos por parte dos cidadãos.

\subsection{REALIZAÇÃo DE TESTES}

Santana \& Guimarães (2006) pesquisaram alunos voluntários do curso de Ciência da Computação do Centro Universitário de Belo Horizonte. Cada um destes estudantes preencheu um questionário que continha inicialmente a avaliação do seu perfil como usuário da Internet e seu respectivo grau de inserção nas atividades sócio-políticas. Posteriormente, eles realizaram três tarefas relacionadas aos sites dos candidatos políticos. Nenhum dado do candidato, seja site ou nome, foi previamente informado, pois a obtenção destas informações integrava a tarefa a ser desenvolvida. O tempo necessário para obtenção destas informações foi cronometrado por cada aluno. As outras tarefas foram: buscar, para cada candidato, o seu currículo e sua proposta para a área de informática. Por fim, cada voluntário avaliou, subjetivamente, a usabilidade dos sites, quanto aos seguintes critérios: design, aparência, navegabilidade, qualidade de informação e consistência de funções (CARROL \& MORAN, 1996).

Esta pesquisa foi realizada com 27 alunos voluntários, também do curso de Ciência da Computação do Centro Universitário de Belo Horizonte, seguindo a mesma metodologia utilizada na pesquisa de Santana \& Guimarães (2006).

\subsection{RESUltados}

A Figura 1 apresenta informações sobre os perfis dos voluntários das pesquisas. Sendo que os participantes de ambas as pesquisas possuem ensino superior incompleto, entretanto, 
trabalham em diversas áreas dentro da Computação.

\begin{tabular}{|c|c|c|c|}
\hline & & $\begin{array}{c}\text { Santana \& Guimaràes } \\
(\mathbf{2 0 0 6})\end{array}$ & Pesquisa Atual \\
\hline \multirow{6}{*}{ 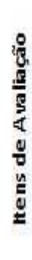 } & Idademédia & 24 anos & 25 anos \\
\hline & Filiados em partidos & $0,00 \%$ & $0,00 \%$ \\
\hline & Hábito diáno de uso da Intemet & $90,00 \%$ & $96,30 \%$ \\
\hline & $\mathrm{Ja}$ acessaram sites de candidatos & $50,00 \%$ & $0,00 \%$ \\
\hline & $\begin{array}{l}\text { Principais motivos para os que nunca } \\
\text { acessaramnenhum site de candidato }\end{array}$ & $\begin{array}{c}\text { Falta de Interesse } \\
(50,00 \%)\end{array}$ & $\begin{array}{c}\text { Falta de Interesse } \\
(73,08 \%)\end{array}$ \\
\hline & Possui parente ou amigo candidato & $20,00 \%$ & $12,50 \%$ \\
\hline
\end{tabular}

Figura 1: Quadro Comparativo sobre Perfil dos Participantes das Pesquisas

Constata-se que, mesmo sendo elevado o percentual de utilização da Internet por parte dos estudantes (em ambas as pesquisas), é baixo o percentual de alunos que já haviam acessado algum site de um candidato antes da pesquisa, sendo $50 \%$ na pesquisa anterior e $0 \%$ na atual, tendo como principal motivo um aumento na falta de interesse político, que cresceu de $50 \%$ para $73,08 \%$ entre as pesquisas. Este pode ser um indicativo do descrédito do grupo com a política brasileira.

A Figura 2 apresenta os resultados obtidos na realização das tarefas considerando os dois principais candidatos. Para cada tarefa, foram medidos os tempos de execução. Não existe um tempo ideal, mas a usabilidade prevê que o usuário possa executar a tarefa usando a ferramenta sem maiores dificuldades. Entretanto, observa-se um aumento considerável no tempo médio máximo para execução de todas as tarefas em relação à primeira pesquisa, passando de 1,40 minutos para absurdos 4,41 minutos em média, mostrando uma dificuldade do usuário em executar a tarefa por falta de usabilidade.

$\mathrm{Na}$ tarefa correspondente à busca do currículo do candidato, o tempo médio máximo passou de 1 para 5 minutos e houve um aumento de $68 \%$ no número de voluntários que não conseguiram realizar a tarefa. Já a tarefa de pesquisar a proposta dos candidatos para a área de informática, a quantidade de entrevistados que não acharam manteve a mesma porcentagem da pesquisa anterior: $37,5 \%$.

\begin{tabular}{|c|c|c|c|}
\hline & & \begin{tabular}{|c}
$\begin{array}{c}\text { Santana \& Guimarães } \\
(2006)\end{array}$ \\
\end{tabular} & Pesquisa Atual \\
\hline \multirow{6}{*}{ 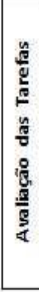 } & \multirow{2}{*}{$\begin{array}{l}\text { Tempo médio total para execução das } \\
\text { tarefas }\end{array}$} & Candidato $1: 1,00 \mathrm{~min}$ & Candidato $1: 2,30 \mathrm{~min}$ \\
\hline & & Candidato $2: 1,40 \mathrm{~min}$ & Candidato $2: 4,41 \mathrm{~min}$ \\
\hline & \multirow{2}{*}{$\begin{array}{l}\text { Não conclusão da tarefa de busca de } \\
\text { curriculo do candidato }\end{array}$} & $\begin{array}{l}\text { Candidato 1:15\% } \\
\text { Média: } 1,00 \mathrm{~min} \\
\end{array}$ & $\begin{array}{l}\text { Candidato } 1: 80 \% \\
\text { Média: } 4,00 \mathrm{~min}\end{array}$ \\
\hline & & $\begin{array}{l}\text { Candidato } 2: 15 \% \\
\text { Média: } 1,00 \mathrm{~min} \\
\end{array}$ & $\begin{array}{l}\text { Candidato } 2: 83 \% \\
\text { Média: } 5,00 \mathrm{~min}\end{array}$ \\
\hline & \multirow{2}{*}{$\begin{array}{l}\text { Não conclusão da tarefa de busca de } \\
\text { proposta para área de informática }\end{array}$} & \begin{tabular}{|l|} 
Candidato $1: 35 \%$ \\
Média: $2,00 \mathrm{~min}$ \\
\end{tabular} & \begin{tabular}{|l|} 
Candidato $1: 25 \%$ \\
Média: $2,25 \mathrm{~min}$ \\
\end{tabular} \\
\hline & & $\begin{array}{l}\text { Candidato } 2: 40 \% \\
\text { Média: } 2,00 \mathrm{~min}\end{array}$ & $\begin{array}{l}\text { Candidato } 2: 50 \% \\
\text { Média: } 2,50 \mathrm{~min}\end{array}$ \\
\hline
\end{tabular}

Figura 2: Quadro Comparativo das Tarefas

As Figuras 3 e 4 apresentam, respectivamente, o histograma e o box-plot com os tempos para execução de todas as tarefas. $81 \%$ dos acessos ocorreram em até 5 minutos. Dois acessos, com tempos acima de 10 minutos foram considerados aberrantes (outliers).

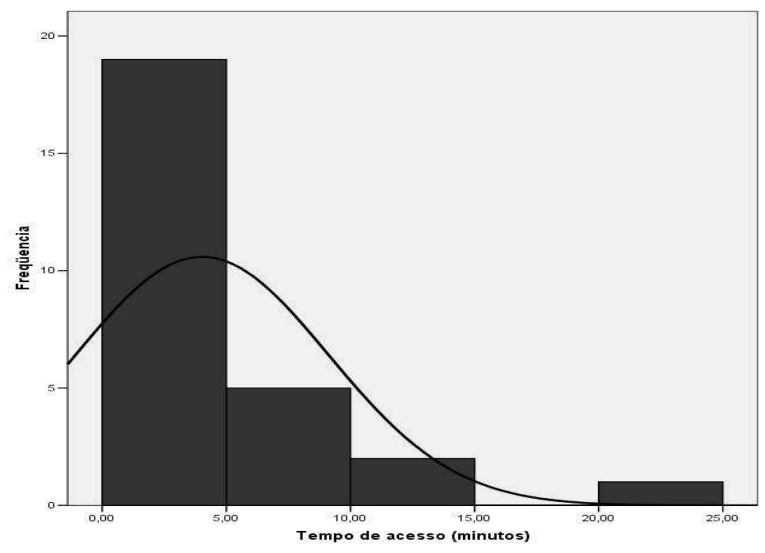

Figura 3: Histograma com o tempo de execução das tarefas

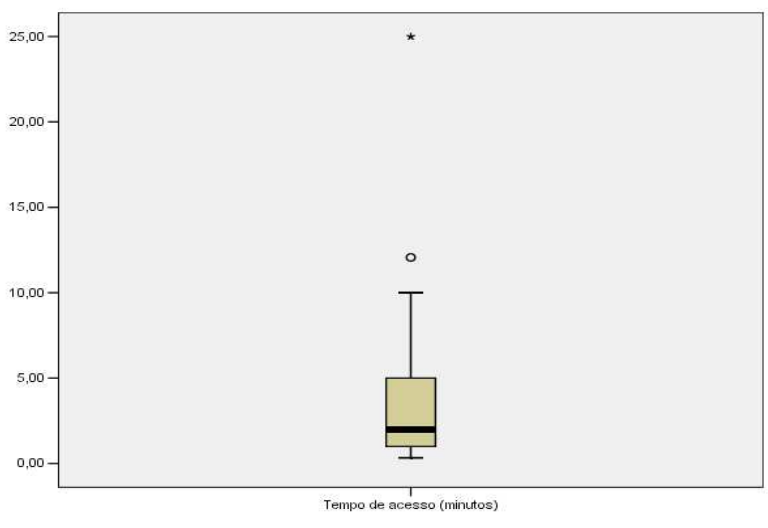


Figura 4: Box-plot com o tempo de execução das tarefas

Algumas considerações importantes dos entrevistados foram que os sites que disponibilizavam informações gerais dos indivíduos não possuíam links diretos para os sites oficiais dos candidatos e, por causa dessa dificuldade em encontrar o site oficial do candidato, alguns voluntários tentaram "burlar" a pesquisa, usando como meio de informação outras páginas, incluindo até mesmo os sites referentes ao cargo atual dos políticos. Os buscadores não retornavam na primeira página de resultados os sites dos candidatos e, por fim, alguns entrevistados relataram que determinados sites eram visualmente agradáveis, entretanto apresentavam deficiência de conteúdo ou dificuldade em encontrar as informações desejadas.

A avaliação da usabilidade dos sites dos candidatos políticos realizada pelas duas pesquisas está ilustrada nas Figuras 5 e 6 . A usabilidade foi avaliada em função de cinco categorias enumeradas como 1 - design, 2 aparência, 3 - navegabilidade, 4 - qualidade de informação, 5 - consistência de função. Essas categorias receberam pelos entrevistados notas de 1 a 5 que, nessa seqüência, correspondem a ruim, regular, aceitável, bom e muito bom.

Percebe-se na Figura 5, referente à primeira pesquisa, que os fatores avaliados apresentaram notas entre 1 e 2 , para o candidato 1 , e entre 2 e 3 para o candidato 2 , para todas as categorias avaliadas, demonstrando assim uma usabilidade insatisfatória. Já na presente pesquisa, representada na Figura 6, pode-se constatar que para todas as categorias avaliadas ocorreram melhoras. Para ambos os candidatos, as notas obtidas foram entre 2 e pouco maior de 3 , indicando uma usabilidade aceitável, porém, pelo fato de envolverem informações políticas, é uma qualificação ainda muito baixa para o efetivo exercício da cidadania.

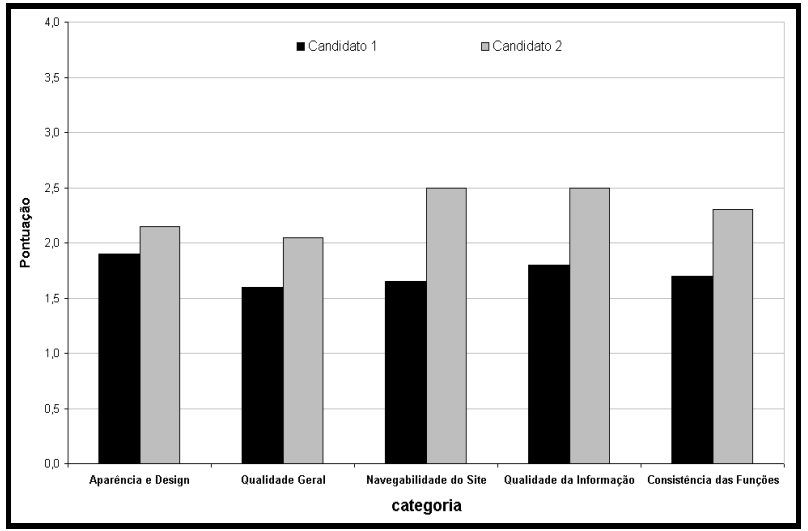

Figura 5: Avaliação dos sites dos candidatos em 2006

Fonte: Santana \& Guimarães (2006)

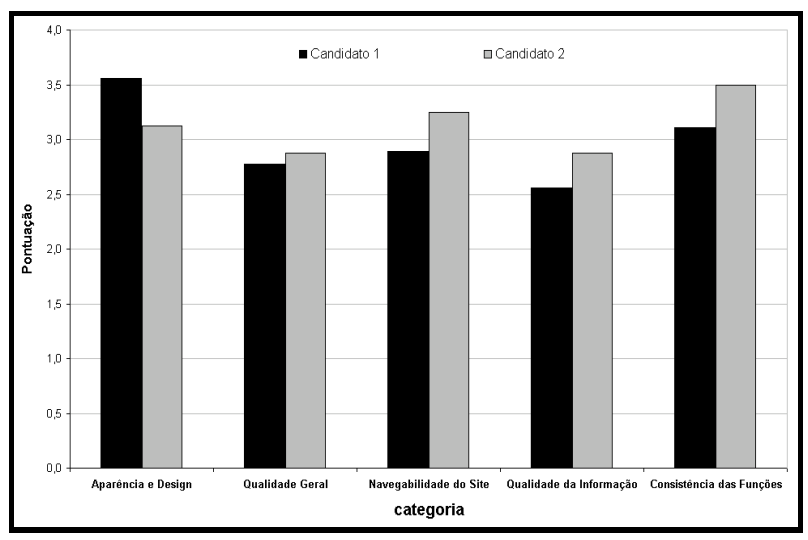

Figura 6: Avaliação dos sites dos candidatos em 2008

\section{Conclusão}

O voto consciente é um fator primordial para o efetivo exercício da cidadania e, para que o indivíduo tenha uma tomada de decisão consciente, faz-se necessário que ele tenha acesso às informações dos candidatos como, por exemplo, por meio dos sites. Portanto, esses devem fornecer condições mínimas de acesso, pesquisa, manipulação e extração de informações, ou seja, usabilidade.

Analisando os resultados obtidos entre as duas pesquisas, os sites políticos não promovem as informações necessárias para a população e, mesmo havendo melhoras na segunda pesquisa, onde os principais fatores de usabilidade se 
apresentaram como apenas aceitáveis, nota-se que a qualidade da informação ainda é deficitária, ferindo a idéia acima sobre a participação política da sociedade no processo democrático. A partir dessas análises, observouse que a população continua não obtendo informações suficientes dos sites para decidir o seu voto, em detrimento do pleno exercício da democracia e cidadania. Cabe a estudos futuros verificar se a falta de usabilidade é decorrente do despreparo da população, da falta de conhecimento técnico por parte dos políticos ou, até mesmo, se a usabilidade está sendo usada de forma maliciosa para que o conteúdo relevante seja preterido ao design gráfico.

\section{REFERÊNCIAS}

BALBONI, M. (2008), "Pesquisa sobre o uso das tecnologias da informação e da comunicação no Brasil 2007", In Comitê Gestor da Internet no Brasil, Acessado em 15 de setembro de 2008, Disponibilizada em http://www.cetic.br/tic/2007.

BRASIL, Código Eleitoral Brasileiro, 2006. "Resolução No 22718", Relator Ministro Ari Pargendler, In Tribunal Superior Eleitoral, Acessado em 28/09/2008, Disponibilizado em http://www.conjur.com.br/pdf/TSE_22718.pdf

CAMARGOS, A. P. (2006), "Usabilidade: o lado humano da inovação tecnológica", Entrevista com Jakob Nielsen, In Revista Fonte, Volume 4.

CARROLL, J. M. e MORAN, T. P. (1996), Desing Rationale: concepts, techniques, and use. New Jersey: LEA.

COUTINHO, M. (2008), "Candidatos 2.0?", In IDG NOW!, Coluna Sociedade Digital, Acessado em 17 de setembro de 2008, Disponibilizado em http://idgnow.uol.com.br/internet/sociedade_digi tal/idgcoluna.2008-05-16.1577740629/.
DALLARI, D. (1998), "Direitos Humanos e Cidadania". São Paulo: Moderna, p.14

GENTILLI, V. (2002), "O conceito de cidadania, origens históricas e bases conceituais: os vínculos com a comunicação", In Revista FAMECOS, Porto Alegre, $n^{\circ}$ 19, dez. 2002, p. 41-55.

GUARINELLO, N. L. (2003), "Cidades-estado na Antigüidade Clássica", In Historia da Cidadania, Organizado por Jaime Pinsky e Carla Bassanezi Pinsky, Editora Contexto.

LAUDON, K. C. e LAUDON, J. P. (2004), "Sistemas de Informações Gerenciais: administrando a empresa digital", $5^{\text {a }}$ edição, São Paulo Perarson/Prentice Hall.

MAIA, R. C. M. (2002), "Redes Cívicas e Internet - do ambiente informativo denso à condições da deliberação pública", In Internet e Política, Organizado por José Eisenberg e Marco Cepik, Editora UFMG, Belo Horizonte, MG, Brasil.

OLIVEIRA, J. P. M. (2003), "Sistemas de Informação e Sociedade", In Ciência e Cultura, Acessada em 06 de setembro de 2008, Disponibilizada em http://cienciaecultura.bvs.br/ scielo.php?script=sci_arttext\&pid=S0009-67252 $003000200023 \& \operatorname{lng}=$ pt\&nrm=iso

RUBIM, A. A. C. (2001), "O lugar da política na sociedade contemporânea", In Lugar Global e Lugar Nenhum, Organizado por José Luiz Aidar Prado e Liv Sovik, Hackers Editores.

SANTANA, M. e GUIMARÃES, C. (2006), "Usabilidade e Cidadania: a falta de usabilidade pode coibir a democracia?", In SBC/III SBSI, III Simpósio Brasileiro de Sistemas de Informação, Curitiba.

SORJ, B. (2003), "Brasil@ povo.com", Rio de Janeiro: Jorge Zahar Editor. 